NBER WORKING PAPER SERIES

\title{
WAGE CONTRACTS WITH INCOMPLETE \\ AND COSTLY INFORMATION
}

Joshua Aizenman

Working Paper No. 1150

NATIONAL BUREAU OF ECONOMIC RESEARCH

1050 Massachusetts Avenue

Cambridge MA 02138

June 1983

The research reported here is part of the NBER's research program in Economic Fluctuations. Any opinions expressed are those of the author and not those of the National Bureau of Economic Research. 


\title{
Wage Contracts with Incomplete and Costly Information
}

\begin{abstract}
Optimal wage indexation, as derived by Gray, was subject to criticism due to a lack of efficient use of information; fallure to clear the market which resulted in non-optimal contracts; and the lack of an explicit use of welfare criteria. The purpose of this paper is to derive a wage contract scheme that is free from the above criticism, but is capable of preserving the insight of Gray's analysis. In so doing the analysis reveals the role of costs of information collection in a world characterized by incomplete information. The analysis focuses also on the interaction between wage indexation and costly information collection as alternative adjustment schemes. It is shown that the first depends only on relative variances, whereas the second also depends on aggregate volat1lity. The justification for labor contracts hinges on the cost of information collection and last minute wage negotiation.
\end{abstract}

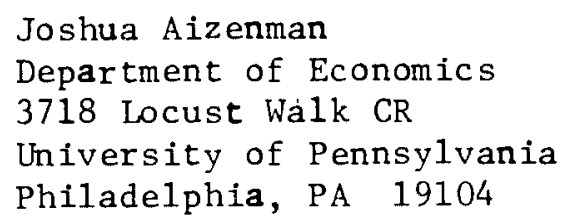




\section{Introduction}

It is well appreciated that an understanding of the structure of labor contracts is a precondition for understanding adjustment to various macropolicies. A labor contract that sets the money wage for a given period introduces a short-run nominal wage rigidity. This rigidity implies that price level changes affect real wage, inducing real effects in the short run. 1 In order to mitigate these effects, the contract might specify a partial degree of wage indexation, and possibly also the conditions under which wage re-negotiation would occur. The literature on wage contract schemes has benefited from contributions by Gray (1976, 1978), Fischer (1977), and others. However, their work has been subject to criticism due to a lack of efficient use of information; fallure to clear the labor market which resulted in non-optimal contracts; and the lack of an explicit use of welfare criteria.

As Barro (1977) and Karni (1983) have pointed out, these models were presented in the context of complete current information. They failed to use all avallable information, and as a result were challenged by the literature on rational expectations. Once a contract scheme uses all available information 1t will, as Barro (1977) and Rarni (1983) have Indicated, dominate Gray's scheme. These models also assumed that employment is demand determined, and, as Cukferman (1980) has pointed out, this assumption is arbitrary. Gray's analysis derives optimal indexation from a loss function given by the output volatility around its full information level. ${ }^{2}$ This is a useful shortcut, but 1t is open to criticism due to the lack of explicit welfare justification.

The purpose of the current paper is to derive a wage contract scheme that does not Incur the above criticlsm, but is still capable of preserving the insight of Gray's analysis. In deriving the scheme, the paper reveals the 
role of incomplete and costly information. ${ }^{3}$ The framework for this analysis Is a monetary economy subject to random shocks. Observed prices provide only partial information regarding the nature of those shocks. The current information set can be Improved by costly data gathering. Suppose that at the end of period $t-1$, a labor contract specifles the wage applied for period $t$. It specifies also the degree of wage Indexation, which will update the contract wage according to the Information provided by the price signal at period t. Because the price signal provides incomplete information, we might benefit by allowing wage re-negotiation under certain conditions. The renegotiation will allow us to rewrite the contract for period $t$ using Improved information. Such information was nota known in the previous period ( $t-1)$, and can be obtalned only by costly information collection (surveys, etc.). The problem analyzed in this paper is to decide ex-ante (at the end of pertod t-1) what welght the contract will allocate for each option. Such a decision should Involve cost-benefit considerations. The presumption is that the administrative cost of wage indexation is small relative to the cost of current information collection and wage re-negotiation. The paper applies expected welfare criterla to designing the desired contract schewe. The analysis does not address the role of risk sharing and Information asymetry in deriving the contract scheme. These factors have been Investigated by Azarlad1s (1975), Bally (1977), Townsend (1982) and others. The current paper does not negate the 1mportance of these factors, rather demonstrates that Information collection and negotiation costs suffice to derive wage contracts In a welfare maximization setup.

Section 2 presents the model. Section 3 derives the desired degree of wage Indexation and wage re-negotiation. Section 4 summarizes the findings. The Appendix provides the notation used in the paper. 
2. The Mode1

Let us take a monetary economy where the labor supply is given by:

(1)

$$
\mathrm{L}_{t}^{\mathrm{s}}=\mathrm{Q}_{s} \cdot\left(\mathrm{W}_{\mathrm{t}} / \mathrm{P}_{\mathrm{t}}\right)^{\delta}
$$

where $W_{t}$ is the money wage and $P_{t}$ the price level at time $t$. Output is given by

$$
Y_{t}=Q_{y} \cdot\left(L_{t}\right)^{h} \cdot \exp \left(v_{t}\right)
$$

where $v_{t}$ is a multiplicative productivity shock, and $L_{t}$ the labor employed at time t.

Money supply is subject to stochastic disturbances $\left(m_{t}\right)$, given by

$$
M_{t}^{s}=\bar{M} \cdot \exp \left(m_{t}\right)
$$

The demand for money balances is given by:

$$
M_{t}^{d}=Y_{t} \cdot P_{t} \cdot \exp \left(-\alpha \cdot E\left(\pi_{t} \mid I_{t}\right)\right)
$$

where $E\left(\cdot \mid I_{t}\right)$ is the conditional expectation operator, which corresponds to the use of information available at period $t\left(I_{t}\right)$, and $\pi_{t}$ is the inflation rate :

$$
\pi_{t}=\left(P_{t+1}-P_{t}\right) / P_{t}
$$


Throughout the paper it is assumed that the information set at time $t\left(I_{t}\right)$ consists of the structure of the model, all variables dated $t-1$ and earlier, and the current price level.

To simplify notation, let us neglect trends in all the variables, assuming that $m_{t}$ and $v_{t}$ are uncorrelated random variables, generated by white noise processes:

$$
x_{t}=N\left(0, \frac{\sigma^{2}}{x} \text { for } x=m, v\right.
$$

As a reference point, we start with the "non-stochastic equilibrium," 1.e., the equilibrium in the economy if the value of all the random shocks is zero $\left(v_{t}=m_{t}=0\right)$. Let us denote by a lowercase variable the percentage deviation of the uppercase variable from its value in the non-stochastic equilibrium. For example, for a variable $x_{t}, x_{t}=\left(x_{t}-x_{0}\right) / x_{0}$ where $x_{0}$ is the value of $x$ if all the shocks are zero. To facilitate discussion, it is useful to take a log-linear approximation of the model around its nonstochastic equilibrium, writing the model in terms of percentage deviations. This is equivalent to the use of a first order approximation of a Taylor expansion around the equilibrium. 4 Frow eq. 2 we get that output at time $t$ is given by

$$
y_{t}=h \cdot 1_{t}+v_{t}
$$

In a flexible, full information economy we get that a competitive labor market implies that:

$$
\hat{1}_{t}=\frac{\delta \cdot d_{1}}{d_{1}+\delta} \cdot v_{t}
$$


where $d_{1}=\frac{1}{1-h}$, and $\hat{x}$ stands for the value of $x$ in a flextble, full Information economy ( $x$ any variable). Denoting real wage by $\tau_{t}$, we get that

$$
\hat{\tau}_{t}=\hat{w}_{t}-\hat{p}_{t}=\frac{d_{1}}{d_{1}+\delta} \cdot v_{t} .
$$

Employment and real wage depend positively on the productivity shock, and are free from monetary considerations in a flexible, full information equilibrium. The case of such an economy is used as a yardstick for the analysis of a contracting economy. Under the labor contract, the wage for period $t$ is pre-set at the end of the previous period. The contract wage is set at its expected money level in a flexible regime, given here by $E\left(\hat{W}_{t} \mid \hat{I}_{t-1}\right)$. $\dot{I}_{t-1}$ stands for the Information set at the end of $t-1$, which is assumed to reflect known shocks $\left(v_{t-1}, m_{t-1}\right)$. The contract we consider contains two provisions that allow limited wage flexibility. First, it allows partial indexation, at a rate of $b, 0 \leq b \leq 1$. Thus:

$$
\log W_{t}^{\prime}=\log E\left(\hat{W}_{t} \mid \hat{I}_{t-1}\right)+b\left[P_{t}^{\prime}-P_{0}\right] / P_{0}
$$

or in a shorter notation

$$
w_{t}^{\prime}=b \cdot p_{t}^{\prime}
$$

where we denote by $x^{\prime}$ the value of $x$ if the wage contract binds $(x=w, p$, etc.). The case $b=1$ corresponds to a full indexation (real wage rigidity). The case of $b=0$ corresponds to zero indexation (nominal wage rigidity). In general, we expect $0<b<1$, providing limlted wage flexibility in the contract scheme. 
Second, the contract specifies conditions under which re-negotiation will occur. The purpose of re-negotiation is to update the contract according to Information that was unknown when the contract was set and is not reflected in the current price level. A re-negotiation is costly. First, there might be direct negotiation costs associated with last minute wage revisions, denoted by $C_{n}$. Next, there might be the real cost of collecting the information needed for the re-negotiation, denoted by $C_{1}$. To model this case, suppose that the current information set at $t\left(I_{t}\right)$ includes only the price level, the past shocks and the structure of the model. At a real cost $\left(C_{1}\right)$, the current information set can be improved to include the value of contemporaneous shocks $\left(m_{t}, v_{t}\right)$. Let us denote the improved information set by $\tilde{I}_{t}\left(\tilde{I}_{t}=I_{t} U\left(m_{t}, v_{t}\right\}\right)$. If a decision is made to re-negotiate, it will imply that resources are to be devoted to improving the information set, and the renegotiated wage will be based upon that set $\left(\tilde{I}_{t}\right) .5$

In the case where the labor market does not clear, employment is assumed to be demand determined. As Cukierman (1980) has shown, this assumption is arbitrary. The current paper demonstrates that under an optimal wage scheme the labor market clears. Thus this assumption is not restrictive, in the sense that alternative rules proposed by Cukierman would yleld the same optimal wage contract scheme, resulting in clearing the labor market. Let us denote by $x^{\prime}$ the value of $x$ if the wage contract binds, and $\dot{x}$ the value if there is re-negotiation. Employment is given by:

$$
\begin{aligned}
& i_{t}^{\prime}=d_{1}\left[E\left(v_{t} \mid I_{t}\right)+p_{t}^{\prime}(1-b)\right] \\
& i_{t}=\frac{\delta \cdot d_{1}}{\delta+d_{1}} \cdot v_{t} .
\end{aligned}
$$


Notice that if the wage contract binds, employment will depend on the perceived productivity shock $E\left(v_{t} \mid I_{t}\right)^{6}$ and on monetary considerations that might affect the price level $P_{t}$. In the case of re-negotiation, it is assumed that the wage is set at its market - clearing level, which reflects the 1mproved information. Using eq. 10 and 11 we get that output is given by:

$$
y_{t}^{\prime}=d_{2}\left[(1-b) p_{t}^{\prime}+E\left(v_{t} \mid I_{t}\right)\right]+v_{t}
$$

$$
\hat{y}_{t}=\hat{y}_{t}-c ; \text { or }
$$

where $c=\left(c_{n}+C_{1}\right) / Y_{0} ; d_{2}=h /(1-h)$.

Notice that in case of re-negotiation output deviates from its level in the full information, flexible equilibrium by the adjustment costs (eq. 13). 7

To complete the description of the labor contract, we should specify the conditions under which re-negotiation is agreed to occur. A possible measure describing the pressure towards re-negotiation is the perceived real shock. We define the re-negotiation pressure, denoted by $\beta_{t}$, as

$$
B_{t}=E\left(v_{t} \mid I_{t}\right)
$$

It is assumed that the contract specifies that if $B$ exceeds a threshold value $(k)$, re-negotiation will occur. ${ }^{8}$ As the analysis will demonstrate, the expected welfare gain due to re-negotiation 1 s proportional to $\left(\beta_{t}\right)^{2}$ (see comment 11). In this sense, $\beta_{t}$ can be used as a measure of the renegotiation pressure. We can summarize the possible states of the economy by 


$$
\left(y_{t}, 1_{t}, \tau_{t}\right)= \begin{cases}\left(\dot{y}_{t}, i_{t}, i_{t}\right) & \text { if }\left|\beta_{t}\right|>k \\ \left(y_{t}^{\prime}, i_{t}^{\prime}, \tau_{t}^{\prime}\right) & \text { if }\left|\beta_{t}\right|<k .\end{cases}
$$

If the wage contract binds, we get incomplete information about the shocks affecting the economy $\left(m_{t}, v_{t}\right)$, summarized by the observed price level $P_{t} \cdot$ Thus

$$
\begin{aligned}
& B_{t}=E\left(v_{t} \mid I_{t}\right)=p_{t}^{\prime} \cdot \rho \\
& \rho=\operatorname{cov}\left(v, p^{\prime}\right) / v_{p^{\prime}},
\end{aligned}
$$

and $v_{p}$, stands for the variance of $p^{\prime}$. Thus, for the case where the wage contract binds, equilibrium in the money market is given by

$$
\mathbf{m}_{t}-\dot{p}_{t}^{\prime}=v_{t}+d_{2}\left[(1-b) p_{t}^{\prime}+\rho \cdot p_{t}^{\prime}\right]+\alpha \cdot p_{t}^{\prime}
$$

Therefore

$$
\dot{p}_{t}^{\prime}=\left(m_{t}-v_{t}\right) /\left[1+d_{2} \cdot p+d_{2}(1-b)+a\right]
$$

Eq. 20 implies that observing the price level provides us with information regarding $m_{t}-v_{t}$. Thus:

$$
B_{t}=E\left(v_{t} \mid I_{t}\right)=\left(m_{t}-v_{t}\right) \cdot \bar{p}
$$

for $\bar{p}=-v_{v} /\left(v_{m}+v_{v}\right)$. Under the wage contract the demand for labor is given by eq. 10 , whereas the supply is given by $l_{t}^{s}=\delta(b-1) p_{t}^{\prime}$. Substituting 
for $\dot{p}_{t}^{\prime}$ (from eq. 17) we get:

$$
1_{t}^{d}-1_{t}^{s}=g \cdot B_{t} ; \text { where } g=d_{1}+(1-b)\left(d_{1}+\delta\right) / p
$$

Alternatively, we can present the excess demand for labor as (see eq. 8, 10):

$$
1_{t}^{d}-1_{t}^{s}=\left[E\left(\hat{\tau}_{t} \mid I_{t}\right)-\tau_{t}^{\prime}\right] \cdot(d+\delta)
$$

Thus, under the contract wage the excess demand for labor is proportional to the re-negotiation pressure $\left(\beta_{t}\right)$. The factor of proportionality $1 \mathrm{~s} g$, and $E\left(\hat{\tau}_{t} \mid I_{t}\right)$ is the market clearing wage. The labor contract described above spectfies two channels of adjustment: the degree of wage Indexation (b) and re-negotiation (k). The next section derives the optimal values of each.

\section{The Optimal Contract Scheme}

In order to derive the desired contract scheme, let us find the welfare deviation from the reference case of a full information flextble economy under a given contract. We denote this measure by WL. Because welfare in the case of a full information, flexible economy is independent of the contract scheme, we can derive optimal $(k, b)$ by minimizing expected WL.

Under full Information, the production of the contract output introduces a welfare loss given by the triangle between the supply and demand of labor. Th1s loss can be approximated by 


$$
W L_{t}^{\prime}=q \cdot \theta_{t}^{2}
$$

where $\theta_{t}=y_{t}^{\prime}-\hat{y}_{t}$, and

$$
q=Q_{s} \cdot\left(\frac{1}{\delta}+1-h\right) /\left(2 h^{2}\right) \cdot \exp \left[\frac{1+\delta}{1+\delta(1-h)} \cdot \log \left(Q_{y} \cdot Q_{s} \cdot h\right)\right]
$$

If re-negotiation occurs, we get welfare loss (relative to the case of

full information) due to the adjustment cost:

$$
\overline{W L}_{t}=c \cdot Y_{0}
$$

Thus, welfare will deviate from the case of full information by:

$$
W L=\left\{\begin{array}{lll}
W L^{\prime} & \text { if } & \left|\beta_{t}\right|<k \\
W L & \text { if } & \left|\beta_{t}\right|>k
\end{array}\right.
$$

The contract for period $t$ is agreed at the end of $t-1$, and it spectfies $b$ and $k$ so as to minimize the expected welfare loss due to the lack of full information: 9

$$
\operatorname{Min} E\left(W L_{t} \mid \hat{I}_{t-1}\right)
$$

Using eq. 12-14 we get that the contract output $\left(y_{t}^{\prime}\right)$ deviates from the flexible, full information output by

$$
\theta_{t}=d_{2}\left[\frac{g}{d_{1}+\delta} \beta_{t}+\gamma_{t}\right] \quad \text { where }
$$

$$
Y_{t}=\left[\left(m_{t}-v_{t}\right) \bar{p}-v_{t}\right] \cdot \frac{\delta}{d_{1}+\delta}
$$


Notice that $\gamma_{t}$ is proportional to the forecast error of $v_{t}$. Therefore, It is orthogonal to $m_{t}-v_{t}$, which is the observed information. On the other hand, $\beta_{t}$ is proportional to $m_{t}-v_{t}$. Thus, $\beta_{t}$ is orthogonal to $\gamma_{t}$. Let us denote by $z$ the normalized value of $k, 1 . e . z=k / \sigma_{\beta}$; and $\Phi(z)$ and $\phi(z)$ the standard normal cumulative distribution and density function. Using the orthogonality of $B$ and $Y$ we get that 10

$$
E\left(W L_{t} \mid \tilde{I}_{t-1}\right)=
$$

$=q\left(\frac{d_{2}}{d_{1}+\delta}\right)^{2} \cdot g^{2} \cdot \nabla_{\beta} \cdot(1-2 \cdot \phi(z) \cdot z-2 \cdot \Phi(-z))+q\left(d_{2}\right)^{2} \cdot v_{\gamma}(1-2 \Phi(-z))+2 \cdot Y_{0} \cdot c \cdot \Phi(-z)$

This equation can be broken down into three components. The first term represents the loss in expected welfare due to the non-clearing labor market that results from the contract. The second term is the welfare loss due to the lack of full information. Both terms apply for those circumstances in which the wage contract binds $\left(\left|\beta_{t}\right|<k\right)$. The third term represents the expected welfare 1088 due to adjustment costs in the case of re-negotiation, and it applies for those clrcumstances in which $\left|\beta_{t}\right|>k$ Notice that a more frequent re-negotiation ( $d k<0)$ reduces the first two terms, increasing the third. 11

To gain further insight, consider figure 1. The two solld curves represent the demand and supply of labor in a "non-stochastic" equilibrium. Under shocks $\left(v_{t}, m_{t}\right)$, the full information demand shifts upward by $v_{t}$, to D'. Due to the lack of full information, the percelved demand shifts upward only by $B_{t}=E\left(v_{t} \mid I_{t}\right)$, to $\bar{D}$. $\Delta$ is the excess demand for labor resulting from the contract wage (conditional on $I_{t}$ ), and $q \cdot \theta_{t}^{2}$ corresponds to the welfare loss relative to the full information case, described by the shaded 
area. The value of the real contract wage $\left(\tau_{t}^{\prime}\right)$ is affected by the indexation arrangement. The optimal policy should design an indexation scheme that wll equate the real contract wage $\left(\tau_{t}^{\prime}\right)$ to the percelved equilibrium real wage $\left(E\left(\hat{\tau}_{t} \mid I_{t}\right)\right)$.

Optimal Indexation

From eq. 29 we conclude that the optimal indexation which minimizes the welfare loss 1s:

$$
b^{*}=1-\frac{1+a}{\left(1+\frac{\delta}{d_{1}}\right) v_{m} / v_{v}+1+\delta}
$$

There are two forces working towards setting optimal indexation. For a monetary shock full indexation $(b=1)$ is desirable becasue it preserves the real wage. For a real shock partial indexation $\left(b=\frac{\delta-q}{1+\delta}\right)$ is desirable because it will generate a real wage that is equal to the wage under a flexible equilibrium. Optimal indexation is set so as to balance those two opposing forces according to their relative importance. Thus a higher $\nabla_{m} / v_{v}$ Implies a higher importance of wonetary shocks, pushing indexation upward. Aggregate volatility, and the cost of information collection are not reflected In optimal Indexation because they do not affect the relative importance of various shocks.

Optimal Indexation is set so as to minimize the expected cost of the nonclearing of the labor market (the first term in eq. 29). It is capable of eliminating this cost completely $\left(g=0\right.$ for $\left.b=b^{*}\right)$. It is useful to note that $b^{*}$ is equal to the indexation proposed by Gray. It is derived here, however, in a framework where the use of information is optimal. The optimality is reflected in the fact that under the proposed scheme the labor market clears $\left(\tau_{t}^{\prime}=E\left(\hat{\tau}_{t} \mid I_{t}\right)\right)$. Any further change can be obtained only by spending real 
resources in information collecting and re-negotiation.

Optimal re-negotiation

We now consider the possibility of government regulation of contract provision. Suppose that wage indexing is prohibited. This implies that $g$ is given by:

$$
g_{0}=d_{1}+\left(\delta+d_{1}\right)\left(\frac{1}{\rho}-d_{2}\right) /\left(1+a+d_{2}\right)
$$

From eq. 29 we get that optimal wage re-negotiation $\left(k^{*}\right)$ is given by: 12

$$
k^{*}=\frac{1}{g_{0}} \cdot \sqrt{\frac{c \cdot Y_{0}\left(d_{1}+\delta\right)^{2}}{q \cdot\left(d_{2}\right)^{2}}-\delta^{2} \cdot \frac{v_{v} \cdot v_{m}}{v_{m}+v_{v}}}
$$

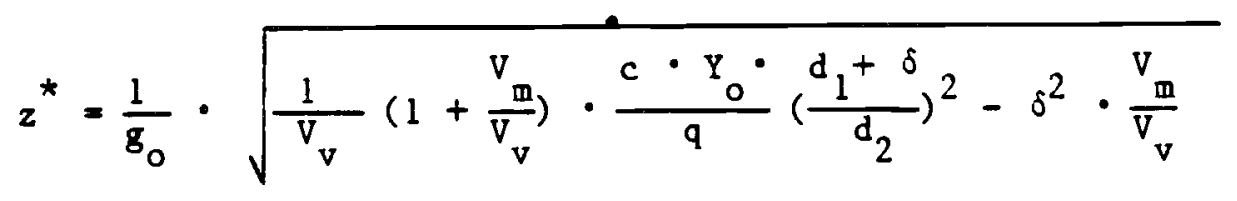

Thus from $32,32^{\prime}$ we get:

$$
\text { a. } \frac{\partial k^{*}}{\partial c}>0 \quad \text { b. }\left.\frac{\partial k^{*}}{\partial v_{m}}\right|_{\frac{v_{m}}{v_{v}}} \text { given }<0
$$

Re-negotiation is desirable if the expected gain exceeds the cost involved. Increase in aggregate volatility (a uniform increase in the variance of all shocks) implies that the potential benefit more frequently justifies re-negotiation (eq. 33b). This is because the cost of lack of full 
information increases monotonically with aggregate volatility. This works as to increase the benefit of re-negotiation, which sets the wage according to the improved information set. Naturally, a higher cost of information collection or last minute re-negotiation reduces the desirability of renegotiation. Notice that if the adjustment cost (c) is small relative to the variance of the real shock forecast error $\left(c \cdot Y_{0}<q \cdot\left(d_{2}\right)^{2} v_{\gamma}\right)$ we get $k^{*}=0$, nullifying the role of pre-set wage contracts. In such a case, all trades take place in spot warkets. To gain further insight into the determination of optimal information collection and re-contracting, let us consider how increasing the frequency of re-negotiation affects expected welfare. This is done by deriving the expected marginal cost and benefit of lowering $z\left(z=k / \sigma_{\beta}\right)$. The expected cost of re-negotiation and information collection is given by the third term in eq. 29. Thus, the expected marginal cost is:

$$
M C==Y_{0} \cdot C \cdot(2 \cdot \phi(z))
$$

The expected benefit of re-negotiation and information collection is given by the first two terms in eq. 29. Thus, expected marginal benefit is

$$
M B=q \cdot\left(d_{2}\right)^{2} \cdot\left(\left(\frac{g_{0} \cdot z}{d_{1}+\delta}\right)^{2} \cdot v_{B}+v_{\gamma}\right) \cdot 2 \cdot \phi(z) .
$$

The expected marginal benefit and cost can be broken down into the marginal benefit and marginal cost weighted by the change in the probability of renegotiation resulting from $d(-z)$ (1.e. $2 \cdot \phi(z))$. Figure 2 plots the unwelghted marginal cost and marginal benefit $(M C /(2 \cdot \phi) ; M B /(2 \cdot \phi)) .13 z^{*}$ corresponds to the optimal re-negotiation. To shaded area weighted by the marginal probability $(2 \cdot \phi)$, corresponds to the welfare gain attributed to 
information collection and re-negotiation. Higher cost c results in an upward shift of the marginal cost curve, implying less frequent re-negotiation. Higher aggregate volatility $\left(d v_{m}>0\right.$ for a given $\left.v_{m} / v_{v}\right)$ shifts the marginal benef1t up, encouraging re-negotiation.

Starting with an economy where wage indexation is prohibited, allowing a limited Indexation has the effect of reducing $g_{0}$. In terms of figure 2 , it shifts the marginal benefit curve to the right, which in turn reduces the frequency of re-negotiation. In this sense, wage re-negotiation and wage Indexation are substitutes for each other. Allowing for unregulated wage indexation will result in setting optimal indexation at $b^{*}$, which in turn Implies that the marginal benefit curve is given by the flat dotted line in f1gure 2.

Consequently, In a covariance stationary economy free from regulations regarding wage indexation, re-negotiation agreements and contracts with optimal indexation are mutually exclusive regimes. Wage contracts with optimal Indexation dominates re-negotiation if and only if the cost of information collection and re-negotiation is large relative to a volatility measure:

$$
\text { c }>\frac{\mathrm{q}}{\mathrm{Y}_{\mathrm{o}}}\left(\frac{\delta \cdot \mathrm{d}_{2}^{2}}{\mathrm{~d}_{1}+\delta}\right) \cdot \frac{\mathrm{v}_{\mathrm{m}} \cdot \mathrm{v}_{\mathrm{v}}}{\mathrm{v}_{\mathrm{m}}+\mathrm{v}_{\mathrm{v}}}
$$

The relevant volatility measure is the varlance of the real shock forecast error $\left(V_{v-\beta}\right)$. If the above condition does not hold, continuous renegotiation will dominate a contract regime. In such a case the labor market behaves as a spot market. In both regimes, the labor market clears continuously. If eq. 36 is satisfied, any regulation which prevents the use of optimal indexation $\left(b^{*}\right)$ gives rise to the simultaneous use of re- 
negotiation and wage contracts; and will occasionally imply disequilibrium in the labor market.

Notice that an unexpected change in the covariance structure can result In a transitory period in which we use a wage indexation that was optimal in a previous regime. In such a case, we might get a transitory disequilibrium in the labor market, resulting from an unstable covariance structure. It should be noted, however, that allowing for the adjustment costs of learning the new structure might preserve the market clearing structure in an extended model. Its formulation is left for future study.

\section{Concluding Remarks}

This paper has focused on how costly information collection and costly last minute wage negotiation affect the flexibility of wage contracts. It considers the case where a wage contract allows for limited flexibility by specifing partial wage indexation and the conditions under which wage renegotiation will occur. The economy is subject to random shocks. Observed prices provide only partial information regarding the nature of those shocks. The current information set can be improved by costly data gatheridg (surveys, research, etc.). Indexation makes use of the information embodied in the price signal, whereas wage re-negotiation make use of the information that can be obtained only by costly research. The analysis derives the contract scheme which will minimize the welfare loss due to Imperfect information at the time of the contract negotiation. A higher volatility in the shocks affecting the economy has the effect of increasing wage renegotiation, whereas a higher cost of information collection reduces it. Wage Indexation proves to depend on measures of relative (and not absolute) volatility of the various shocks. It is not affected by the cost of 
Information collection. Wage Indexation Increases with the Importance of monetary, relative to real, disturbances. It is the same as the Indexation scheme proposed by Gray, but it is derived in a setup which uses all avallable information, resulting in a clearing labor market. The final justification for labor contracts with optimal wage re-negotiation hinges on the cost of information collection and last minute wage negotiation.

In a covarlance stationary economy, free from regulation regarding wage Indexation, re-negotiation agreements and contracts with optimal indexation are mutually exclusive regimes. Wage contracts with optimal indexation dominates re-negotiation if (and only if) the cost of information collection and re-negotiation is large relative to a volatility measure. If this condition does not hold the labor market behaves as a spot market. If this condition is satisfied, any regulation which prevents the use of optimal Indexation gives rise to the simultaneous use of re-negotiation and wage contracts.

\section{Comments}

1. For studies that emphasize these effects see, for example, Fischer (1977) and Taylor (1979).

2. Flood and Marion (1982) and Marston (1982) use such a loss function to derive optimal wage policy in an open economy. Alzenman (1982) applies this loss function to derive optimal wage re-negotiation. The above studies use a modified version of models used by Gray (1976) and Fischer (1977).

3. In some respects, this paper can be viewed as extending Barro's (1977) analysis for the case of costly and incomplete information. 
4. It is assumed that the variances of the shocks are small enough to make such an approximation useful.

5. To simplify exposition, it is assumed that investment in improving the information set is found in conjunction with re-negotiation. Modifying this assumption will not change the nature of the results reported in the paper. This is because the only observable current information is the price level. Optimal indexation allows us to use this information efficiently. Therefore, re-negotiation can improve welfare only if it is based upon information that is not contained in the price signal. Thus, Investment in information must accompany re-negotiation. If the costs of re-negotiation are high relative to the costs of information collection, we expect investment in information to precede the decision related to re-negotiation. Modeling such a sequence can be added without difficulty and without affecting the main results.

6. This is because the producer demands labor such as to equate product wage with the percelved marginal product. Because he does not observe $v_{t}$, he uses $E\left(v_{t} \mid I_{t}\right)$.

7. The cost $c$ is assumed not to affect the marginal product of labor. Thus $\hat{y}_{t}-c$ is a logarithmic approximation of the output around the nonstochastic equilibrium.

8. A related analysis of a price adjustment model is developed in Barro (1972).

9. Because of lack of full information, the best that we can do is to use the Information avallable at the contract negotiation time $\left(\bar{I}_{t-1}\right)$.

10. To derive eq. 29 we use the fact that

$$
(\sqrt{1 \pi})^{-1} \int_{-z}^{z} x^{2} \cdot \exp \left(-x^{2} / 2\right) d x=
$$




$$
\begin{aligned}
& (\sqrt{2 \pi})^{-1} \int_{-z}^{z}\left[\exp \left(-x^{2} / 2\right)-\left(x \exp \left(-x^{2} / 2\right)\right)^{\prime}\right] d x \\
& =1-2 \Phi(-z)-2 \cdot z \cdot \phi(z) .
\end{aligned}
$$

11. For a known value of $B_{t}$, the expected benefit form re-negotiation 1s:

$$
E\left(q \cdot \theta_{t}^{2} \mid I_{t}\right)=q\left(\frac{d_{2} \cdot \delta^{2}}{d_{1}+\delta}\right)\left[\left(\frac{g}{\delta}\right)^{2} \cdot \beta_{t}^{2}+v_{v-\beta}\right]
$$

It is proportional to $\beta_{t}^{2}$. Thus, $\beta_{t}$ can be used as a measure of re-negotiation pressure.

12. $k^{*}=0$ if the expression in the squareroot is negative.

13. Figure 2 corresponds to the assumption that $c \cdot Y_{0}>q\left(d_{2}\right)^{2} V_{\gamma}$. 
Uppercase variables denote levels, lowercase letters denote the logarithmic deviation of the uppercase variable from the "non-stochastic equilibrium."

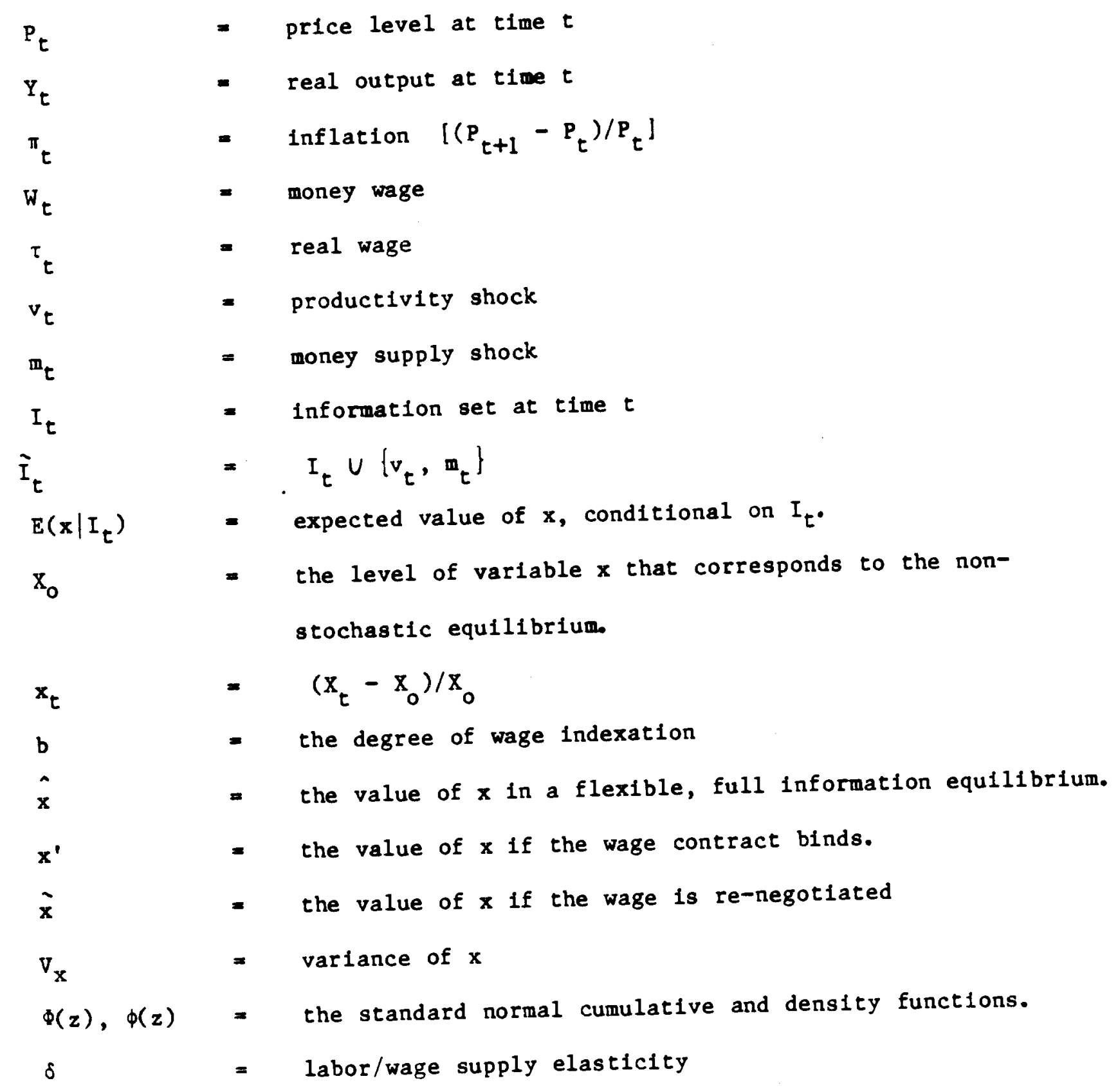


= output/labor supply elasticity

$d_{1}=1 /(1-h)$

= labor/wage demand elasticity

$\mathrm{d}_{2}$

$=h /(1-h)$

$\beta_{t}$

$=$ re-negotiation pressure $=E\left(v_{t} \mid I_{t}\right)$ 


\section{References}

Alzenman, J. "Wage Re-Negotiation In a Closed and Open Economy", manuscript, University of Pennsylvania, 1982.

Azariadis, C. "Implicit Contracts and Underemployment Equilibria", J.P.E. 83, no. 6 (December 1975): 1183-1202.

Ba1ly, M.N. "On the Theory of Layoffs and Unemployment", Econometrica 45 (July 1977): 1043-63.

Barro, R.J. "A Theory of Monopolistic Price Adjustment", R. E.S. 39 (January 1972): 17-26.

"Long Term Contracting, Sticky Prices and Monetary Policy",

J.M.E. 3(1977) 305-316.

Cuklerman, A. "The Effects of Wage Indexation on Macroeconomic Fluctua-

t1ons: A Generalization", J.M.E. 6(April 1980): 140-147.

Fischer, S. "Wage-Indexation and Macroeconomic Stability", J.M.E., supplement (Carnegie-Rochester Conference Series, vol. 5): 107-147.

Flood, R.P. and N. Marion "The Transmission of Disturbances Under Alternative Exchange-Rate Regimes with Optimal Indexing". Q.J.E. (1982): 43-66. Gray, J.A. "Wage Indexation: A Macroeconom1c Approach" J.M.E. (Apr11 1976): 221-35.

"On Indexation and Contract Length," J.P.E. (February 1978):

1-18.

Karn1, E. "On Optimal Wage Indexation", J.P.E. 91, (Apr11 1983): 282-292.

Marston, R.C. "Real Wages and the Terms of Trade: Alternative Indexation

Rules for an Open Economy", NBER Work1ng Paper \#1046 (December 1982).

Taylor, J.B. "Staggered Wage Setting in a Macro Model". A.E. R. 69 (May 1979) : 108-13. 
Townsend, R.M. "Optimal Multiperiod Contracts and the Gain From Enduring Relationships Under Private Information". J.P.E. 90, no. 6 (December 1982): $1166-1186$. 


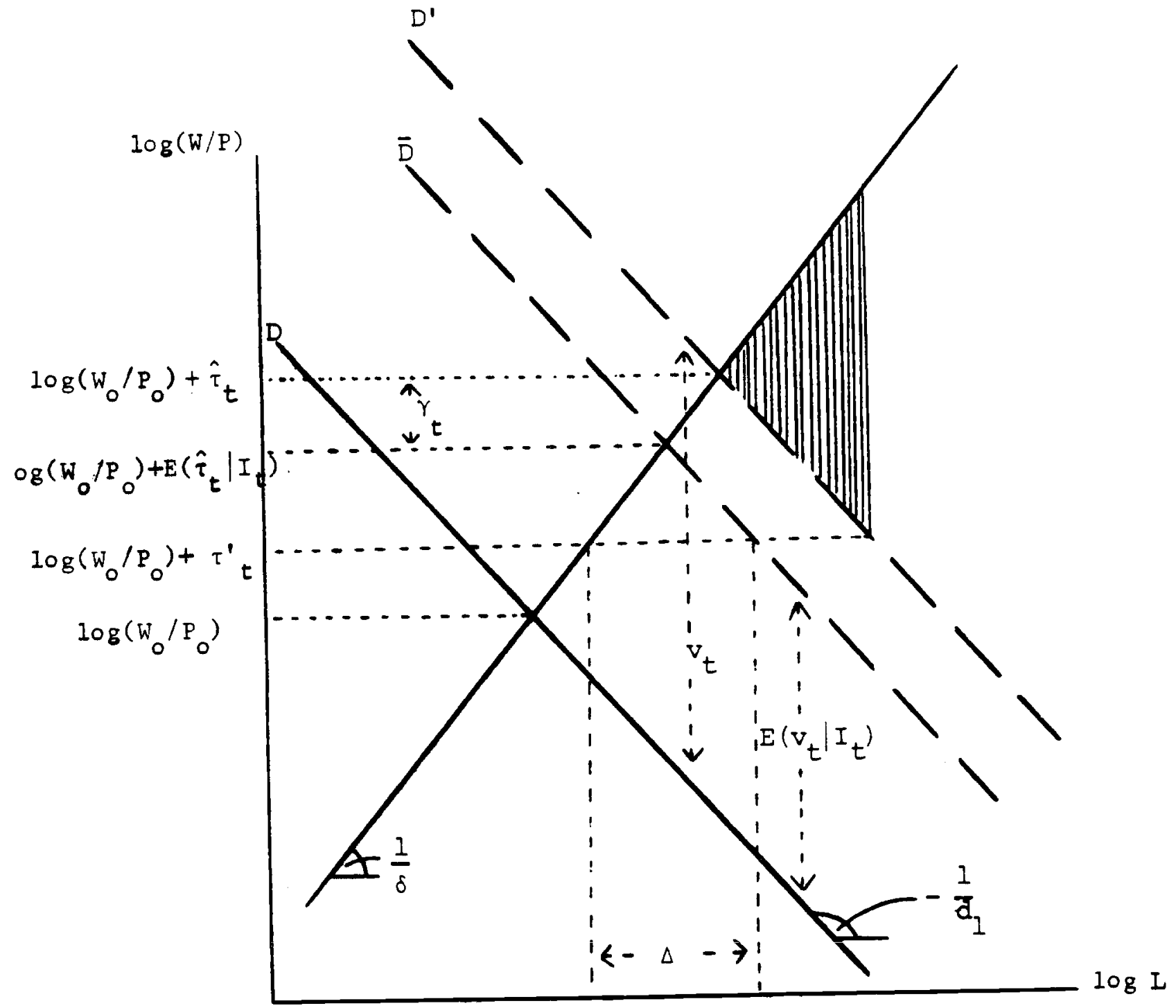

Figure I

LABOR MARKET EQUILIBRIUM 


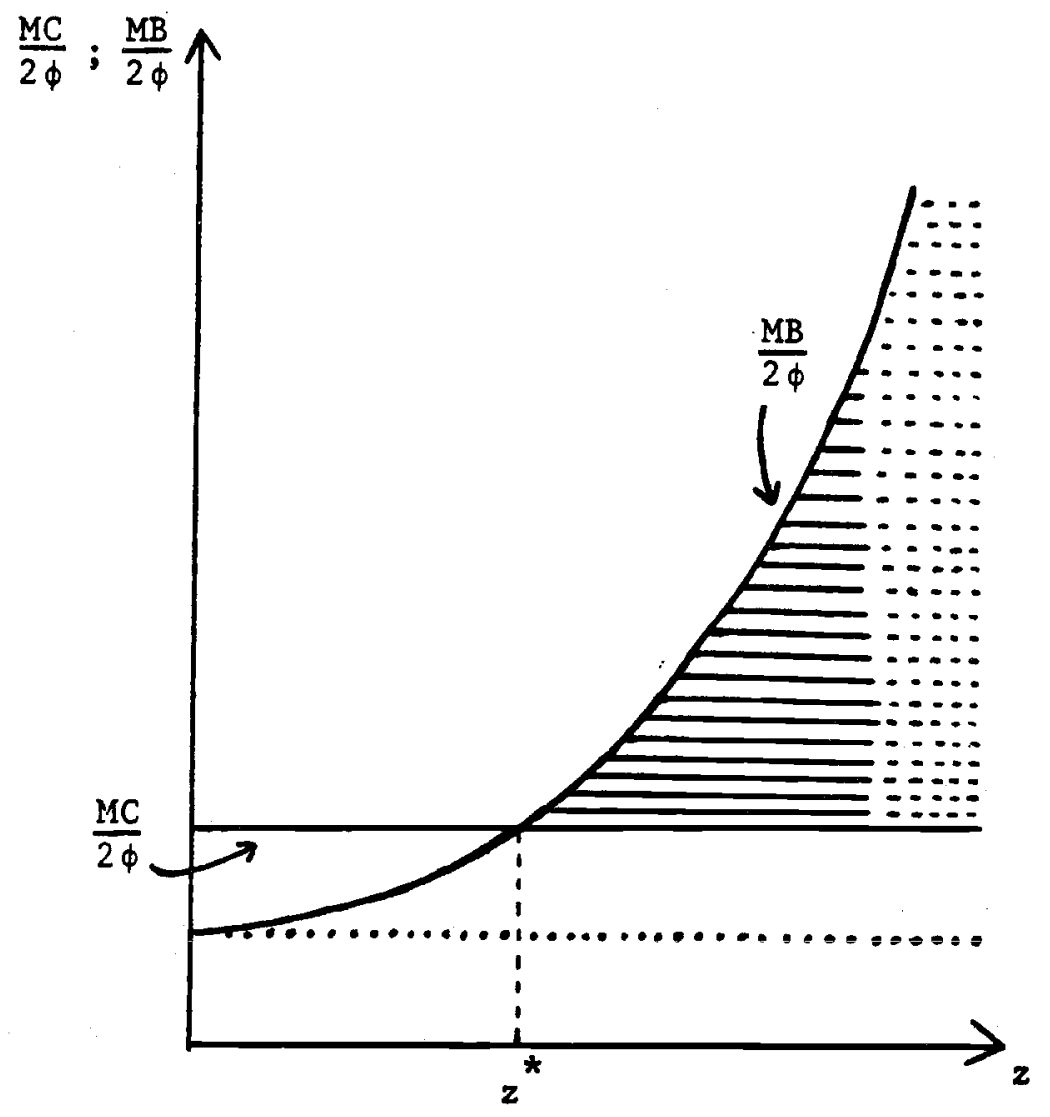

Figure 2

OPTIMAL RE-NEGOTIATION 